\title{
COMPARATIVE ANALYSIS OF THE ELEMENTS OF ATTACK AND DEFENCE IN MEN'S AND WOMEN'S GAMES IN THE ESTONIAN VOLLEYBALL HIGHEST LEAGUE
}

\author{
Raini Stamm, Meelis Stamm, Doris Torilo, Kaivo Thomson, \\ Alexander Jairus \\ School of Natural Sciences and Health, Tallinn University, Estonia
}

\begin{abstract}
The aim of this study was to analyse the differences between men's and women's teams of the Estonian highest league in attack, serve, block, defence and serve reception. The sample consisted of 5 men's and 5 women's teams of the Estonian volleyball highest league in the 2014/2015 season. To collect data, two game videos of each team were watched; from them tempo of attack, type of attack, block and serve, and the results of defence and cover were registered. In addition, statistics created by the Data Volley and Volleysoft 6-3 programs on the basis of expert assessments were used to estimate the efficiency of volleyball elements and results of reception. SPSS Statistics 23 version for Windows was used to construct frequency tables and multinomial logistic regression analysis was applied to find the probable frequencies of the activities analysed. The results revealed that in Estonian men's highest league games quick tempo 1 attacks were used statistically significantly more often than in women's games. Men were more proficient at attack and used a vigorous spike more often than women. For both genders, double block was the most often used block type. Broken double block was more common to men than to women. The serve type most often used by men was the power jump serve, followed by the tactical float serve. Women most often used the standing serve and, as second, the jump float serve. Men made more serve errors than women did. The percentage of ace serves was also higher in women than in men.

In defence, the percentage of the ball remaining in play was higher in women than in men, and women's defence cover was more efficient than
\end{abstract}


men's. As a result of attack cover, the ball remained in play nearly by half more frequently in women's than in men's games. Nonetheless, women scored fewer points as a result of attack cover. Serve reception in the Estonian highest league was better in men, and men made statistically significantly fewer errors in reception than women did.

Keywords: volleyball; performance; gender specificity; Estonian volleyball highest league

\section{INTRODUCTION}

Performance in volleyball depends on many internal and external factors that are developed, perfected and changed during practice in order to achieve success.

In 2010, a thoroughgoing study of differences between men's and women's game was conducted. João et al. analysed the World Cup 2007 games, assessing the differences between men's and women's games. A total of 132 matches were analysed. The authors state that men are taller, jump higher, the centre of gravity is higher in their bodies, which gives them greater potential and more opportunities to perform different technical elements in the game (e.g., power jump serve, strong attacks, blocking). For example, the physical advantages that differentiate men from women guarantee that men score more points at attacks from all the most often used zones (zones 1, 6, 4, 3 and 2). This, in its turn, gives more opportunities to the setter for greater diversity of sets. Likewise, high jumping ability provides opportunities for the power jump serve in order to score a point immediately or, as an alternative, to create difficulties for the opponents at reception and building a new attack. Still, the study revealed that, although men have certain physical advantages that can be transferred to technique and tactics, male volleyball players also make many errors, particularly in conclusive activities (attack, block and serve). A study conducted in 2005 also observed the speed of the ball at attack. In men, the speed of the ball was from 61.2 to $112.3 \mathrm{~km} / \mathrm{h}$. In women, it was between 45.8 and $82.5 \mathrm{~km} / \mathrm{h}$. These results explain the differences at attack and definitely influence greatly the speed of attack and the opportunities for using different zones for attack. Better opportunities for attack may increase the number of errors in defence. The results of that study proved that the number of balls put in play at defence was considerably higher in women [15].

In addition, the time of ball exchanges (from the serve by one team to scoring of a point by either of the teams) is longer in women than in men. 
The difference in strength is also mentioned. As women do not apply as much strength at attack as men do, this guarantees longer ball exchanges between the two teams and greater continuity of attack and defence. Good defence gives women greater proficiency than to men [15].

C. Fernandez-Echeverria et al. propose that women should use the jump serve when they could profit from the jump, and when the jump is accompanied by certain aggressiveness, so that the serve would be more efficient and not only involve greater risk, which includes the probability of losing a point [13].

Volleyball begins from the serve, and the serve is the basis for present-day elite volleyball. Its successful performance enables the team to directly earn a point or to make if more difficult for the opposing team to build up a successful attack; this way the serve essentially influences the further course of the match. The serve is considered the primary means of attack in elite teams [28].

N. Marelic states that elite teams more often risk at serve in order to neutralise the strong attack by the opposing team and to increase their own team's chances for a successful block [22].

Although the correlation between the victory of the match and block is lower than in the case of attack and serve, in men the efficiency of block is a differentiating feature of elite teams [24].

Blockers use two different strategies at block. A difference is made between the anticipatory strategy where the blocker acts according to the activity of the setter of the opposing team and the experiential strategy where the blockers predict the activity of the setter based on the experience of possible solutions to the situation [1]. Earlier research has shown that anticipatory strategies of blocking have not proved successful in elite men's volleyball. Not using such strategies is more likely to be associated with the higher efficiency of the block. In volleyball, anticipatory strategies of the block have very different roles. Anticipatory strategies are successful only in certain situations, e.g. in quick attack from one foot from behind the setter's back in zone 2. In women's elite volleyball, it is most essential for the blocker to have the opportunity for the 1st tempo attacker to perform the attack [2].

Several authors $[11,26,12,21,24]$ have reached the conclusion that the attack has a very great influence on the victory or the loss of the match. In elite volleyball, the mean sum of points won by attack is 45.46 , by block 10.1 and by serve 4.98 [18]. Marcelino et al. find in their study of 2005 World League games that the correlation between the victory and the attack was very strong $(\mathrm{r}=0.81)$. It can be concluded from their results that the attack as one of the conclusive activities greatly influences the result of the match [19]. 
In addition to the tempo of the attack, the type of the attack has also been analysed. In this case the attack is characterised either as spike or decoy. This classification has been used by many authors who have analysed the attack [27, $29,23,8]$.

Each following step in volleyball greatly depends on the previous one. This sequential system guarantees that each following step depends on the performance of the previous activity. There are authors $[3,4$,$] who state that the first$ touch influences the second and the third, or the performance of the setter and the attacker greatly depends on the precision of defence [6].

As earlier literature has shown, in men's and women's volleyball, success is granted by different performance of technical elements, as men and women differ in their strength, speed, dexterity, jumping ability, and thus, by their capability of performing volleyball elements, which also determines the use of different tactics for achieving success in the game. Therefore, the aim of this study was to find which ways of performing volleyball elements are used by the men's and women's teams of the Estonian highest league in attack, serve and block, and to analyse the differences in attack and defence in men's and women's teams.

\section{METHODS}

\section{Sample}

The sample consisted of the teams who played in the Estonian highest league in the 2014/2015 season. The games of five women's and five men's teams were analysed. In total, ten matches by women's teams and ten matches by men's teams were assessed. The data were collected using the volleyball statistics programs Volleysoft 6-3 ja Data-Volley 2007. In addition, video recordings of the matches were used. The following volleyball elements in men's and women's games were analysed: attack, serve, reception of serve, block and defence. In total, the analysis included 8142 activities.

\section{ATTACK}

For attack, the statistical program provided information on the total number of attacks, errors, attacks into block and attacks from which points were scored. To assess the tempo of attack, the classification of Selinger and AckermannBlount [27] was used. It divides the tempo of attack into three classes, which were assessed after the matches from video recordings. 
1. Tempo 3. The attacker starts to perform the steps of spike after the ball has left the setter's hands and has reached the highest point on its trajectory. A slow tempo.

2. Tempo 2. The attacker starts to perform the steps of spike immediately after the ball has left the setter's hands; the jump always follows that. It is performed two or three steps after the performance of the set.

3. Tempo 1. The attacker performs the spike steps before the ball has left the setter's hands and jumps at the moment when the setter touches the ball. A quick tempo.

In addition, the type of the attack was established, which could be done when watching video recordings after the matches. The attack was divided into two types, which have been used by Selinger and Ackermann-Blount and many other authors [8]:

1. Strong serve The ball is hit forcefully and the direction of its movement after the spike is downwards or towards the ground.

2. Tip. The ball is hit with controlled force, not with maximum force. The ball is placed on a defenceless area on the opponents' side of the court.

\section{BLOCK}

About the block, the statistical program provides information only about blocks that ended with scoring a point and about block touches after which the ball remained in play and defence. As necessary information, a response can be obtained on points earned by block. To get a better overview of the use of the block and its tactics, the classification used by Costa et al. [10] in their study was applied:

1 . Triple block, $3 \times 3$. Three frontline players perform a group block against the attacker. During blocking, the blockers' hands are side by side.

2. Triple block with a hole, $(2+1) \times 1$. Three frontline players perform a group block where two blockers are side by side, but one blocker is at a distance from the others, leaving an opening in the block.

3. Double block, $2 \times 1$. Two frontline players perform a group block. During blocking, the blockers' hands are side by side.

4. Double block with a hole $(1+1) \times 1$. Two frontline players perform a group block, but the blockers are at a distance from each other, leaving an opening in the block.

5. Single block, $1 \times 1$. One frontline player performs a block.

To the five-point classification, the authors of this paper added two features which are not reflected by the statistical program (video recordings were used 
to collect data). In the authors' opinion, however, they gave essential information on blocking and the players' decisions on the court.

6. "Empty net". The blocker(s) do not manage to block the attacker or do not perform a block to the attack.

7. "Hitting out of hands". The ball is hit out of the blockers' hands; it goes out of bounds and the point is given to the attacking team.

\section{SERVE}

For serve, the statistical program provides an overview of the total number of serves, the number of errors made, the number of ace serves and the efficiency percentage. Serves can be performed with different techniques and in different styles the knowledge of which also gives added value to the analysis of performance.

E.g.: The power jump serve is one of the ways of attack; it is difficult for the opponents to receive it, and this gives an advantage to the serving team. However, the risk of error is also great when performing a power jump serve. By performing a simple serve, the risk of error is diminished, but the opponents are given a better chance to organise their attack.

To assess the type of the serve, video recordings were used. To assess the technical differences of women's and men's volleyball, the combined scale of classifications applied by Costa et al [10] was used.

The serve was divided into the following categories:

1. Power jump serve - the ball is forcefully hit from the jump, a characteristic feature is the spin of the ball.

2. Tactical spin serve - similar to power jump serve but less force is applied to hit the ball. Smaller application of force enables the player to concentrate attention on targeting the serve to the planned place on the opponents' side of the court.

3. Strong jump float serve - the ball does not spin and flies to the opponents' side close over the net

4. Tactical float serve - the ball does not spin and flies higher over the net. The server performs the serve seeking for a definite player or place on the court.

$\underline{5}$. Standing serve - the serve is performed without a jump.

\section{DEFENCE}

The authors of the current study also wanted to compare the defence of men and women, and separately, the attacker's cover, which means bringing back into play of the ball that has been hit into the block during the attack. 
To obtain the results, the authors collected information from video recordings about the efficiency of counter-attacks after defence. For this purpose, all the defence activities were registered. All the balls coming across the net from the side of the attacking team to the side of the defending team were counted as defence (spikes, decoys and balls hit over the net were taken into account).

Defence and the activities following it were divided into three categories:

1. "Point" - the ball brought up from defence which was followed by a set and attack or an immediate attack, and a point was scored for the team.

2. "Loss of point" - error by the player in defence in brining the ball into play.

3. "Into play" - the ball brought into play in defence, which is followed by a set or an attack; the team does not score a point, but the opponents perform their own defence and can organise an attack.

The similar three categories were used when collecting data on the attacker's cover. The categories were based on the attack cover criteria of Laporta et al. [16].

In the case of defence, the authors of the study assess the final result because, when assessing only playing the ball up in defence, we can understand how good or bad the defence is in the team under observation, but we do not get information about how the defence influences the final result or scoring the point and how this is expressed in men's and women's games of the Estonian highest league.

\section{Data Analysis}

SPSS Statistics 23 version for Windows was used to construct frequency tables, and multinomial logistic regression analysis was applied to find the probable frequencies of the activities analysed. Logistic regression analysis, or the logistic model in general, predicts the probability of happening of the event under study and changes in it depending on changes in the continuous dependent variable [17]. For descriptive statistics, the data from the games were recorded in the Microsoft Excel 2010 program. Volleysoft 63 and Data Volley 2007 volleyball recording programs were also used for data collection and primary analysis.

\section{RESULTS}

\section{ATTACK}

The results revealed that tempo 1 attack was more often used by women than by men (17.8 and $13.7 \%$ respectively). Tempo 2 attack was more often used by men's teams $(75.1 \%)$ than by women's teams $(60.7 \%)$. Tempo 2 attack was pre- 
dominant in both genders. The difference between men and women appeared in tempo 3 and tempo 1 , as men used tempo 3 or the slow attack least of all the tempos of attack (11.2\%), which refers to the faster attack action in men's games and to the tendency to attack against one blocker or against a broken block. In women's teams of the Estonian highest league, however, tempo 3 attacks were more frequent than tempo 1 attacks.

The results of multinomial regression analysis showed that in men's teams the probability of performing a tempo 1 attack compared to tempo 3 was 1.48 times higher than in women's teams $(\mathrm{p}<0.05)$. In the case of tempo 2 attack, compared to tempo 3, the probability of performance of tempo 2 was 1.8 times higher in men than in women $(\mathrm{p}<0.05)$.

In addition to the speed of the set, the type of the attack was assessed. It was divided into two - spike - a powerful hit; decoy - directing the ball to an empty place on the opponents' side of the court. The types of 1975 attack activities were analysed (women 1114; men 861). Compared to the attack tempo, the number of activities was different, as it was not possible to register the tempo in the case of all attacks, when no organised set preceded the attack.

The results revealed that both men and women used vigorous spikes more often than decoys (women 75.5\% and men 83.7\%). The difference between men and women lay in the relation between using the decoy and the spike. Women used the decoy in games $8 \%$ more than men did (women $24.3 \%$ and men $16.3 \%)$.

Regression analysis results showed that men used the vigorous spike compared to the decoy with 1.7 times greater probability than women $(\mathrm{p}<0.05)$.

The assessment of efficiency of technical elements showed that women's attack activity had lower proficiency than men's. The difference between men and women in the percentage of attack errors was small (women 9.3\% and men $8.8 \%$ ). The difference appeared in the case of attack into block where men lost more points than women did (men 9.2\% and women 6.3\%). The greatest difference between men and women was in the efficiency of attack and scoring of points. Men gained a point from $46.2 \%$ of attacks (the lowest percentage in the games observed was $42 \%$, the highest $53 \%$ ). Women gained a point from $36.2 \%$ of attacks (the lowest percentage in the games observed was $24.5 \%$, the highest $45.8 \%)$.

\section{BLOCK}

A total of 1858 blocks were analysed (women 995; men 863). The block type was assessed in six categories; for detailed description, see Methods. 
The results revealed that both men and women most often used the double block, which includes two players (women $49.2 \%$ and men $45.8 \%$ ). In women's games, the $1 \times 1$ situation where the attacker was opposed by a single blocker occurred more often than in men's games. Out of the 995 blocks performed by women, none was a triple block. Men used the triple block 69 times out of 863 performances (8\%).

Additionally, the situations were assessed where the blockers were not able to organise a united block, and an opening remained between the players' hands $(2+1)$. As women did not perform any triple blocks, there were no " $2+1$ " situations where one blocker is situated at a distance from the two others. In men, the " $2+1$ " situation occurred in $2.1 \%$ of cases or 18 times.

A double block where there is a gap between the player's hands occurred in $20.4 \%$ of blocking situations in women and in $20.7 \%$ in men, which means that each fifth block was an incorrectly formed double block, which gave an advantage to the attacker. Although the percentages were nearly equal in both men and women, multinomial regression analysis showed that, compared to the correct double block, the incorrectly formed double block $(1+1)$ was 1.09 times more predictable in men than in women $(\mathrm{p}<0.05)$.

"Empty" means the situation where the opponents' attack is not blocked, either because of the setter's perfectly performed set that deceives the blockers, or the blockers do not consider it necessary to block the attack. These situations mostly occurred in the game when the set was performed far from the net, and the attack zone was at the back. In women, the absence of block occurred in $6.8 \%$ of situations when the opponents performed an organised attack. In men, the percentage of the same situation was $5.3 \%$.

In addition, the points lost due to blocking were counted during data collection. This category included the blocks where, as a result of the attack, the ball bounced out of bounds from the blocker's hands. There was a remarkable difference between men's and women's results; women lost points 67 times during blocking (6.7\%). Men, however, lost 113 points out of 863 blocks (13.1\%).

Men gained points by blocking 78 times out of 863 blocking activities (9.04\%) and women 72 times out of 995 (7.24\%).

Out of all the double blocks performed by men, $31.2 \%$ were broken blocks or incorrectly formed double blocks, which can be explained by the speed of men's attack tempo. In women, broken double blocks formed $29.3 \%$ of all the double blocks, which was also a high percentage. Although women performed more attacks with a slow tempo, the authors would like to note that women's errors in organising the block did not occur only because of the speed of the 
attack but also because of the insufficient mastery of the double block technique, as players were too far from each other during blocking.

\section{SERVE}

The analysis of serve was based on the way of performing the serve. A detailed description of the serve techniques analysed is given in Methods. A total of 1493 serves were assessed (women 733 , men 760).

The results revealed that nearly half of the serves (women $40.8 \%$ and men $43.6 \%$ ) were tactical float serves, which were targeted at a certain player or a certain zone. A great difference between men and women lay in the use of the power jump serve and the standing serve. None of the women players performed the power jump serve. Men performed the power jump serve in $47.9 \%$ of cases. Women, on the contrary, performed $49.1 \%$ of serves without a jump or used the standing serve. None of the men used this serving technique.

Both men and women used the tactical spin serve and the strong jump float serve to a small extent (respectively, women $3.3 \%$ and men $4.2 \%$, and women $6.8 \%$ and men $4.3 \%$ ). Comparing the results of multinomial regression analysis based on the jump float serve, men performed the stronger version of this serve style or the strong jump float serve with 0.6 times greater probability than women $(\mathrm{p}<0.05)$. The probability of performance of the tactical spin serve compared to the tactical float serve was 1.2 times greater in men than in women $(\mathrm{p}<0.05)$.

The data collected from volleyball recording programs revealed that in the Estonian highest league men erred at serve more often than women did (men at $16.7 \%$ and women at $12.4 \%$ of serves). In the Estonian highest league, men's teams erred 15.9 times per game on average and women's teams 9.1 times. The results showed that the majority of serves remained in play in both men and women (men $76.7 \%$ and women $80.2 \%$ ). This can be explained by the choice of the serve type. When the tactical float serve is performed, the receivers have more time for reaction, as the trajectory of the ball is not straight and sharp but curved and directed to a certain point.

The percentage of immediately gaining a point from the serve or ace serves was higher in women than in men (women $7.4 \%$, men $6.7 \%$ ). The difference is not very great, but considering men's greater number of errors at serve, it can be concluded that in Estonian men's volleyball highest league risk does not pay off, and greater attention should be paid to improving the serve. Summing up the efficiency of serve in men's and women's games in the Estonian highest league, it could be said that the efficiency of serve was very equal (men $42.56 \%$ 
and women $42.68 \%$ ). In the Estonian women's highest league, the efficiency of the tactical float serve was greater, as with the same efficiency as in men, more ace serves were performed and fewer errors occurred.

\section{DEFENCE}

In data analysis, defence activities were divided into two categories - defence and cover. Defence included bringing the ball into play in the case of opponents' attack or block touch. Cover included situations where a player of the attacking team performs an attack into the opponents' block and the ball is directed back to the side of the attacking team and is brought into play. A total of 1293 defence activities (women 723, men 570) and 234 covers (women 129; men 105) were assessed.

In the current study, the basis for assessment of the efficiency of defence is the final result of the defence.

The analysis of defence activities showed that, in both men and women, defence often ended in losing a point (in men $47.3 \%$ and in women $57.4 \%$ of the cases). Defence was considered not performed if, during the attack, the ball landed within the bounds of the court, as a result of defence, the players did not manage to transfer the ball to the opponents' side, or they were not able to score a point from the attack organised from the defence. The percentage of the ball remaining in play was higher in women (35.8\%) than in men (25.4\%), which can be explained by women's lower application of force during attack; therefore, there was more time for reaction in the defence zone and bringing the ball into play. The smallest difference in building up an attack from defence was in the percentage of balls from which a point was scored - in women $16.9 \%$ and in men $17.2 \%$. This means that less than each fifth defence activity ended by gaining a point.

If this is compared with the results of multinomial regression analysis, the ball exchanges remaining in play, compared to defences ending with losing a point, in men they ended with 0.59 times greater probability of the ball remaining in play, which is more than by half less than in women $(\mathrm{p}<0.05)$. The probability of gaining a point from defence was also higher in women. If gaining a point was compared with losing a point, it was 0.84 times $(\mathrm{p}<0.05)$ more probable that a men's team would gain a point as a result of defence than a women's team would.

The poor result of defence in men's teams of the Estonian highest league can be explained by the high proficiency of attack, which refers to the high level of attack in men of the Estonian highest league. At the same time, errors made at 
block were also more frequent in men; therefore, it was more difficult for the defenders to choose a place in the defence zones. In women, the number of errors at block was also great, and the choice of the right place in the defence zone was complicated.

In cover, the result was similar to defence. Most often, both men and women lost a point as a result of an error in the attack organised from the cover or because of incorrect cover (women 55.8\% and men 66.7\%). There was a greater difference in the number of balls remaining in play. In women, the balls brought up from the cover remained in play in as much as $34.9 \%$ of cases, but in men, in $19 \%$ of cases. This can also be explained by women's weaker attack activities, which gives them longer time of ball exchange and longer continuation of the play. The amount of covers ending with a point was $9.3 \%$ in women and $14.3 \%$ in men.

The results of multinomial regression analysis showed that if the balls remaining in play are compared with points lost by men and women, in men the 0.46 times more probable result was the ball remaining in play than the loss of a point, which means that in women the probability the ball remaining in play as the result of the cover was nearly by half greater than in men $(p<0.05)$. At the same time, the probability that the attack ends with scoring a point rather than losing it was 1.29 times higher in men's than in women's games. This means that women won points from cover statistically significantly less often men $\operatorname{did}(\mathrm{p}<0.05)$.

\section{RECEPTION}

The data on reception were collected from the recording program during the games. The program gave information on the total number of receptions in every match, errors of serve reception, the percentage of positive receptions and the percentage of very good receptions (a very good reception was registered when the setter could use all the zones of attack).

A total of 1289 serve receptions were analysed (women 659, men 630).

The results revealed that in men the percentage of positive receptions was 52.15 (the highest result in the analysed matches $62 \%$, the lowest result $37.76 \%$ ) and in women 48.99 (the highest result in the analysed matches $58.3 \%$, the lowest result $35.95 \%$ ). Men also had a higher percentage of very good receptions than women had. Men's percentage of very good receptions was 27.3 (the highest result in the analysed matches $34 \%$, the lowest result $22 \%$ ). Women's result, however, was 24.19 (the highest result in the analysed matches $34.8 \%$, the lowest result 13.2\%). Women made more errors at serve reception than could be 
expected. Women erred 58 times out of 659 receptions, which is $8.8 \%$ of receptions. Men erred 41 times out of 630 receptions, which is $6.5 \%$ of receptions.

Multinomial regression analysis results showed that women were 0.72 times more likely to make an error at serve reception than men were $(\mathrm{p}<0.05)$.

\section{DISCUSSION}

Compared to men, women's game is characterised by slower tempo of attack and more frequent use of the decoy. Women contribute more to the activities in the defence line, and the more frequent use of the decoy grants the longer continuation of ball exchanges. One of the reasons can be that women use the decoy more often because they are afraid to risk, as the performance of a strong attack increases the possibility of errors, and women pay greater attention to blocking the opponents' attack and to the defence line than men do [10]. At the same time, women in the Estonian highest league had a greater number of attacks hit into the block and a greater number of errors. Compared to men, the proficiency of women's attack was lower. Men gained a point from $46.2 \%$ of attacks. Women gained a point from $36.2 \%$ of attacks. Comparing these results with attack efficiency in other countries, men's mean result in World Championship games in 2011 was $50.2 \%$ and in Brazilian women's Super League in the $2011 / 2012$ season $-38.7 \%[5,10]$.

Castro et al. state in their study on men's attack that strong attack correlates with gaining more points [7]. This was also reflected in the current study where men's attack was more proficient than women's, and men used the vigorous spike more often as the type of attack. Afonso and Mesquita [2] stated in their study that the decoy was accompanied by the continuation of ball exchange, as the slow attack gives the defender more time for reaction. This also results in the longer duration of women's games and lower percentage of realisation of attacks [2].

In the case of serve, the performance of the tactical float serve was characteristic of both men and women. Both men and women used this technique for nearly half of the serves. Concerning the other half, the power jump serve was predominant in men and the standing serve in women. Men made significantly more serve errors. Comparing these results with the elite volleyball teams of 2003, a difference could be found in the men's teams of the Estonian highest league in the relation between the jump serve and the float serve. The elite men's teams of the world most often used the power jump serve (70.3\%), followed by the jump float serve (21.9\%), and the standing float serve was used the least 
often (7.7\%). In the European championship of club volleyball in 2002, the power jump serve constituted $99.2 \%$ of all men's serves [28]. Therefore, it can be stated that the share of the power serve in the men's teams of the Estonian highest league is too small.

The studies on women's serve in elite volleyball revealed that women's most preferable serve was the standing float serve ( $48.6 \%$ of all serves). The share of the jump float serve in women was surprisingly small (17\%) [25]. In the women's teams of the Estonian highest league, the proportion between the tactical float serve and the standing serve was more equal. The data collected from the statistics revealed that in the Estonian highest league men erred at serve more often than women did (men at $16.7 \%$ and women at $12.4 \%$ of serves). According to Marelic, a successful team should not err at serve more than three times per match. In the Estonian highest league, men's teams erred 15.9 times on average per match and women's teams 9.1 times. Marelic also states that the power jump serve used in the game increases the risk of error, but in the case of success, it neutralises the building of the attack by the opponents [22].

In the Finnish men's highest league, the percentage of serve errors was $12.2 \%$, which is significantly lower than in the Estonian men's highest league; the most preferable serve type was the power jump serve (54\%) and the share of the jump float serve was $30 \%$ [14].

The study by Costa et al. where men's and women's game was compared said that women performed the power jump serve in $17.1 \%$, the tactical spin serve in $7.3 \%$, the strong jump float serve in $16.9 \%$, the tactical float serve in $20.7 \%$ and the standing serve in $38 \%$ of cases. Compared to the results of this study, the women's teams of the Estonian highest league performed significantly fewer strong float serves and never used the power jump serve [9].

The high efficiency of attack in men was caused by the low use of the serve, as good reception enables the setter to use different zones of attack and to perform quicker sets.

To the authors' surprise, serve reception was weaker in women than in men, which could also cause the lower use of tempo 1 and the greater use of tempo 3 at attack. The serve is considered the primary means of attack in the game [28]. In the men's teams of the world's best volleyball countries (Brazil, Russia, Poland, Argentina), the highest percentage of positive receptions was $66.46 \%$ and the lowest $46.53 \%$, and the percentage of errors in games was between 2.48\% and 9.9\% [5]. Comparing these results with the results of the Estonian highest league, it can be stated that reception in Estonian men's teams is good. The study of the women of the Brazilian super league showed that the percent- 
age of very good receptions was $49.6 \%$, which is by half better than the results of the women's teams in the Estonian highest league [10]. Men's good percentage of reception and high percentage of realisation of attacks in the Estonian highest league games, however, refers to the low use of the serve as the primary means of attack in men's games. Women's lower percentage of reception shows that the women's teams of the Estonian highest league should concentrate more on practising the improvement of reception.

In the case of block, the double block was most characteristic of both men and women. Nearly half of the blocks included two players. The number of broken double blocks was great in both men and women. In men's games, this was caused by the high tempo of attack; therefore, the blockers had little time for reaction. In women, the reason was errors in organising the block, not only because of the speed of the attack but also because of the low mastery of the technique of the double block, as the players remained too far from each other. Compared to the Brazilian women's super league, the results were similar to the Estonian highest league. Most often, women used the double block (46\%). The percentage of broken double block in Brazilian women's teams was 25.7, which was higher than in the women's teams of the Estonian highest league [10].

A study conducted in 2007 revealed that, in the men's World Cup of 2007, the teams also most often used the double block (58.6\%). Triple blocks were used more often than in the Estonian highest league. The study did not separately show broken double blocks [20]. A similar result was reached in the current study where both men's and women's teams used the double block most often. The quicker the tempo of the attack, the more difficult it is for the opponents to form double blocks [2].

In both men and women, defence and cover were characterised by a great number of errors and lost points. Because of the women's weaker attack activities in both defence and cover, the number of balls remaining in play was greater than in men. A study on cover where a similar three-point system was used to assess cover in women's games revealed that $22.9 \%$ of covers ended in an error, $54.5 \%$ ended in the ball remaining in play, and $23.5 \%$ ended in gaining a point [16]. Comparing this with the results of the current study, it can be said that Estonian women's cover was weaker and needs improvement. In a study of 2007, it was stated that in the elite teams of the world, $1 / 3$ of defence situations ended in an error and a loss of point to the opposing team. Our study revealed that in the Estonian volleyball highest league, the loss of point occured in a half of the situations in both men and women (women $47.3 \%$, men 57.4\%). 


\section{CONCLUSIONS}

In the Estonian men's highest league games, quick tempo 1 attacks were statistically significantly more frequent than in women's games. Men were more proficient at attack and used a vigorous spike more often than women did.

For both genders, the most often used block type was the double block. Broken double block was 1.09 times more probable in men than in women $(\mathrm{p}<0.05)$.

The serve type most often used by men was the power jump serve, followed by the tactical float serve. Women most often used the standing serve and, as second, the jump float serve. Men made more serve errors than women did. The percentage of ace serves was also higher in women than in men.

In defence, the percentage of the ball remaining in play was higher in women than in men, and women's cover was more efficient than men's. As a result of cover, the ball remained in play nearly by half more frequently in women's than in men's games. Nonetheless, women scored points from cover more seldom $(\mathrm{p}<0.05)$.

Serve reception in the Estonian highest league was better in men, and men made statistically significantly fewer errors in reception than women did $(\mathrm{p}<0.05)$.

\section{REFERENCES}

1. Afonso J., Mesquita I., Marcelino J., Silva J. (2010). Analysis of the setter's tactical action in high-performance women's volleyball. Kinesiology, 42(1), 82-89.

2. Afonso J., Mesquita I. (2011). Determinants of block cohesiveness and attack efficacy in high-level women's volleyball. European Journal of Sport Science, 11(1), 69-75.

3. Barzouka K., Nikolaidou M.E., Malousaris G., Bergeles N. (2006). Performance excellence of male setters and attackers in Complex I and II on volleyball teams in the 2004 Olympic Games. International Journal of Volleyball Research, 9, $19-24$.

4. Bergeles N., Barzouka K., Nikolaidou M.E. (2009). Performance of male and female setters and attackers on Olympic-level volleyball teams. International Journal of Performance Analysis of Sport, 9, 141-148.

5. Bozhkova A. (2013). Playing efficiency of the best volleyball players in the world. Federation of the Sports Pedagogues of the Republic of Macedonia, 41(1), 92-95.

6. Castro J., Mesquita I. (2010). Analysis of the Attack Tempo Determinants in Volleyball's Complex II - a Study on Elite Male Teams. International Journal of Performance Analysis of Sport, 10, 197-206. 
7. Castro J., Souza A., Mesquita I. (2011). Attack efficacy in volleyball: elite male teams. Perceptual and Motor Skills, 113(2), 395-408.

8. Costa G., Ferreira N., Junqueira G., Afonso J., Mesquita I. (2011). Determinants of attack tactics in youth male elite volleyball. International Journal of Performance analysis in Sport, 11(1), 96-104.

9. Costa G., Afonso J., Brant E., Mesquita I. (2012). Differences in game patterns between male and female youth volleyball. Kinesiology, 44(1), 60-66.

10. Costa G., Afonso J., Barbosa R., Countinho P., Mesquita I. (2014). Predictors of attack efficacy and attack type in high-level Brazilian women's volleyball. Kinesiology, 46(2), 242-248.

11. Cox R.H. (1975). The relationship between selected volleyball skills components and team performance of men's Northwest Double A Volleyball Teams. Dissertation, University of Oregon, United States.

12. Díaz J. (1996). Analysis and meaning of the technical, tactical and competitive behavior of masculine volleyball in the Games of the XXV Olympiad in Barcelona. Dissertation, Seville University, Spain.

13. Fernandez-Echeverria C., Gil A., Moreno A., Claver F., Moreno M.P. (2015). Analysis of the variables that predict serve efficacy in young volleyball players. International Journal of Performance Analysis of Sport, 15, 172-186.

14. Häyrinen M., Lahtinen P., Mikkola T., Honkanen P., Paananen A., Blomqvist M. (2009). Serve efficiency in men's volleyball. Research Institute for Olympic Sports.

15. João P.V., Leite N., Mesquita I., Sampaio J. (2010). Sex differences in discriminative power of volleyball gamerelated statistics. Percept Mot Skills, 111(3), 893-900.

16. Laporta L., Nikolaidis P., Thomas L., Afonso J. (2015). The Importance of Loosely Systematized Game Phases in Sports: The Case of Attack Coverage Systems in High-Level Women's Volleyball. Monten. J. Sports Sci. Med, 4(1), 19-24.

17. Kaart T. (2012). Binaarsete tunnuste analüüsimeetodid. Eesti Maaülikool. Õpiobjekt.

18. Marcelino R., Mesquita I. (2006). Characterizing the efficacy of skills in high performance competitive volleyball. Notational Analysis of Sport - VII (pp. 491-496).

19. Marcelino R., Mesquita I., Sampaio J. (2008). The weight of term actions in volleyball. Contributions of the spike, serve and block for the teams' rankings in the World League 2005. International Journal of Performance Analysis in Sport, 88(2), 1-7.

20. Marcelino R., Mesquita I., Sampaio J. (2010). Effects of the volleyball game actions related to the quality of opposition. The Open Sports Sciences Journal, 3, 89-94. 
21. Marelić N., Žufar G., Omrčen D. (1998). Influence of some situation-related parameters on the score in volleyball. Kinesiology, 30(2), 55-65.

22. Marelić N., Rešetar T., Zadražnik M., Đurković T. (2005). Modelling of situation parameters in top level volleyball. $4^{\text {th }}$ International Scientific Conference on Kinesiology, Opatija, Croatia.

23. McLaughlin J. (2006). Attacking. In K. LeNoerg (Ed.), Volleyball skills and drills: American Volleyball Coaches Association. Champaign, IL: Human Kinetics, 53-68.

24. Palao J., Santos J., Ureña A. (2004). Effect of team level on skill performance in volleyball. International Journal of Performance Analysis in Sport, 4(2), 50-60.

25. Quiroga M.E., Carcia-Manso J.M., Rodrigez-Ruiz D., Sarmiento S., De Saa Y., Moreno M.P. (2010). Relation between in-game role and service characteristics in elite women's volleyball. Journal of Strength and Conditioning Research, 24, 2316-2321.

26. Santos J.A. (1992). Study of variations in performance of elite volleyball teams through information obtained by computerized statistical system. Dissertation, University of Granada, Spain.

27. Selinger A., Ackermann-Blount J. (1986). Arie Selinger's power volleyball. New York: St. Martin Press.

28. Seppa A. (2013). Erinevate rünnakutegevuste efektiivsus võrkpallis. Tartu Ülikool, Spordipedagoogika ja treeninguõpetuse instituut. Bakalaureusetöö.

29. Weishoff P. (2002). Attacking. In D. Shondell and C. Reynaud (Eds.), The volleyball coaching bible. Boston: Human Kinetics, 199-226.

\section{Address for correspondence:}

Raini Stamm

Tallinn University

School of Natural Sciences and Health

Narva street 29, 10120 Tallinn, Estonia

E-mail: raini.stamm@tlu.ee 